\title{
FORMAC̄̃̃O DE LEITORES NO PROGRAMA FEDERAL MAIS EDUCAÇÃO
}

\section{READER EDUCATION IN THE FEDERAL PROGRAM MORE EDUCATION}

\section{Sadi Zaffonato Júnior}

Pós-Graduado em Teorias e Metodologias da Educação. Professor de Língua Inglesa na Escola Estadual de Ensino Fundamental Bandeirantes; na Escola Estadual de Ensino Médio Ponche Verde e nas Escolas Municipais de Ensino Fundamental João Antônio de Col e Linha Secco, no município de Sertão/RS. Endereço: Avenida Getúlio Vargas - 428. E-mail: jrzaffonato@gmail.com

\section{Alexandra Ferronato Beatrici}

Doutora em Educação, Professora no IFRS - Campus Sertão. Rodovia RS 135,

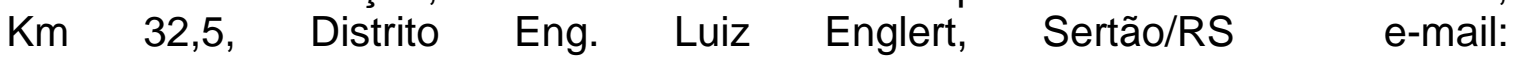
alexandra.beatrici@sertao.ifrs.edu.br

\section{Resumo}

Este artigo busca compreender como as práticas leitoras, dentro do Programa Mais Educação, ajudam a desenvolver o gosto pela leitura nos alunos participantes deste. Foi realizado levantamento de dados, utilizando-se como metodologia a pesquisa etnográfica, bibliográfica, além de análise de questionários aplicados a alunos do $5^{\circ}$ ano da Escola Estadual de Ensino Fundamental Bandeirantes, do município de Sertão/RS. Com base nos fundamentos teóricos de Gadotti (2006), Moll (2009), Lajolo (1993 e 1997) e Zilberman (1988), entende-se que cabe ao professor a realização de um trabalho consciente envolvendo diversas práticas de leitura, buscando sempre transformações nos sujeitos envolvidos. O professor pode e deve exercer um papel muito importante no sentido de estimular o aluno a se tonar um leitor habitual, inclusive de forma lúdica. Para que isso ocorra, o profissional da educação deve demonstrar entusiasmo nas práticas leitoras, a fim de que seus alunos se espelhem. Observou-se que durante o período em que os alunos estão na escola frequentando o Programa Mais Educação, ficam mais expostos aos livros, à contação de histórias e a debates sobre obras, o que contribui com o desenvolvimento do gosto e da curiosidade sobre os livros. As práticas desenvolvidas durante a pesquisa contribuíram com os incentivos dados pela escola, auxiliando na formação de sujeitos mais autônomos, criativos e críticos.

Palavras-Chaves: Leitura. Mais Educação. Educação em Tempo Integral. 


\section{ABSTRACT}

This article seeks to understand how the reading practices, within the Mais Educação Program, help to develop a taste for reading in students participating in it. A data survey was carried out, using as methodology the ethnographic and bibliographic research, in addition to the analysis of questionnaires applied to 5th grade students of the Bandeirantes State Elementary School, in the city of Sertão/RS. Based on the theoretical foundations of Gadotti (2006), Moll (2009), Lajolo (1993 and 1997) and Zilberman (1988), it is understood that it is up to the teacher to carry out a conscious work involving several reading practices, always seeking transformations in the subjects involved. The teacher can and should play a very important role in stimulating the student to become a habitual reader, even in a playful way. For this to happen, the educational professional must show enthusiasm in the reading practices, in order for his students to mirror him. It was observed that during the period when the students are at school attending the Mais Educação Program, they are more exposed to books, to storytelling, and to debates about books, which contributes to the development of their taste and curiosity about books. The practices developed during the research contributed with the incentives given by the school, helping in the formation of more autonomous, creative and critical subjects.

Keywords: Reading. More Education. Full-Time Education

\section{INTRODUÇAO}

O presente artigo é um recorte de pesquisa maior ${ }^{1}$ realizada no ano de 2016 e tem como objetivo refletir sobre as práticas leitoras dos estudantes do 5ำ ano do Ensino Fundamental no Programa Federal Mais Educação da Escola Estadual Bandeirantes, localizada no município de Sertão/RS. Devido à verificação do desinteresse pela leitura por parte dos estudantes do $5^{\circ}$ ano, foi realizada pesquisa com o objetivo de verificar o porquê de tal comportamento. Observou-se que, a maioria dos estudantes não possui contato com materiais de leitura em suas residências, o que se configura como um fator de desestímulo à ação de ler. Enquanto alguns têm acesso a materiais diversificados de leitura, grande parte somente tem contato apenas no ambiente escolar. Essas dificuldades de acesso são constatadas devido às famílias serem economicamente carentes, pela falta de apoio/incentivo familiar e, ainda, pela localização de suas residências em áreas rurais, inclusive quilombolas e bairros

\footnotetext{
${ }^{1}$ A pesquisa intitulada Formação de Leitores no Programa Mais Educação foi requisito para a conclusão do Curso de Especialização em Teorias e Metodologias da Educação, do IFRS/Campus Sertão. Tendo como orientadora a professora Alexandra Beatrici
} 
periféricos.

Sabe-se que a leitura é importante na vida das pessoas principalmente em fase escolar, especialmente nos anos iniciais do Ensino Fundamental. Nesse sentido, Foucambert (1994), ressalta a importância da leitura e o poder que esta pode propiciar, permitindo que os cidadãos leitores se destaquem na sociedade em relação aos não leitores, pois, além de agregar conhecimento, a leitura contribui também para o desenvolvimento de um pensamento, de um raciocínio reflexivo, lógico, crítico e interpretativo, facilitando, desta forma, tanto a comunicação oral quanto a produção de textos. No momento em que o estudante adquire o hábito da leitura, gradativamente vai propiciando uma mudança de comportamento, no modo de pensar, de sentir e de agir, oportunizando, assim, uma melhor comunicação, facilitando a convivência grupal e social, além de resultar em crescimento pessoal. Por meio da prática leitora, visa-se estabelecer um elo, ou seja, uma ponte entre professor e estudante no sentido de aproximar, de desenvolver no estudante o gosto pela leitura. Ler, além de ser um direito, é também uma forma de inclusão social, pois forma sujeitos críticos capazes de ver e ler a realidade do mundo de múltiplas formas.

Para a pesquisa e análise reflexiva deste texto, utilizou-se vários autores, entre eles Gadotti (2009), Moll (2009), Gatti (2006), Luck (2006), Abreu (2002), além de documentos do Ministério da Educação e Cultura (MEC), que abordam questões sobre Educação, Educação em Tempo Integral e o Programa Federal Mais Educação.

\section{BREVE CONTEXTUALIZAÇÃO DO PROGRAMA MAIS EDUCAÇÃO}

Um dos primeiros documentos que aparece a ideia de Educação Integral foi o Manifesto dos Pioneiros da Educação Nova em 1932, sendo idealizado por Fernando de Azevedo, Anísio Teixeira, Cecília Meireles, entre outros vinte e três intelectuais brasileiros, que teve como objetivo estabelecer um sistema de Ensino Público no Brasil capaz de integrar diversas formas de aprendizagem: leitura e escrita; saúde; ciências físicas e sociais; aritmética, artes industriais; educação física; desenho; música; dança e alimentação. Também defendia a educação integral como um "direito biológico" de cada indivíduo e como dever do Estado, que deveria garanti-lo: 
[...] do direito de cada indivíduo à sua educação integral, decorre logicamente para o Estado que o reconhece e o proclama, o dever de considerar a educação, na variedade de seus graus e manifestações, como uma função social e eminentemente pública, que ele é chamado a realizar, com a cooperação de todas as instituições sociais [...]. Assentado o princípio do direito biológico de cada indivíduo à sua educação integral, cabe evidentemente ao Estado a organização dos meios de o tornar efetivo. (AZEVEDO, 1932).

Conforme pode-se observar no trecho retirado do documento redigido pelo professor, educador, crítico, ensaísta e sociólogo Fernando de Azevedo (18941974), aparece a defesa entre outras coisas, do direito das pessoas à educação de qualidade e de tempo integral, com o estado tendo uma função principal dentro desse sistema: a de organizar e tornar efetivo esse modelo de educação.

A educação em tempo integral, sempre esteve em debate, e foi vista como uma forma de melhorar a qualidade de ensino e a formação dos estudantes. Diversas metodologias e práticas foram utilizadas para atingir estes objetivos. Pensando nisso, no governo do presidente Luiz Inácio Lula da Silva, foi criado o Programa Mais Educação, no ano de 2007, como uma maneira de se implantar a educação em tempo integral em todo o país.

O Programa Federal Mais Educação ${ }^{2}$ foi instituído pela Portaria Interministerial número 17 de 24 de abril de 2007, e visa fomentar a educação integral de crianças, adolescentes e jovens, por meio do apoio a atividades socioeducativas no contra turno escolar. Compreende-se que a educação integral em jornada ampliada no Brasil é uma política pública em construção e um grande desafio para gestores educacionais, professores e comunidades que, ao mesmo tempo, amplia o direito à educação básica e colabora para reinventar a escola.

O que se quer dizer, aqui, com reinventar a escola, não significa começar

\footnotetext{
2 Para instituir esse programa o Governo Federal contou com o apoio dos Ministros da Educação; do Desenvolvimento Social e Combate à Fome; do Esporte e do Ministro de Estado da Cultura, embasado no inciso Il do parágrafo único do art. 87 da Constituição Federal, do Art. 34 da Lei de Diretrizes e Bases da Educação Nacional, Lei no 9.394, de 20 de dezembro de 1996 que determina a permanência do aluno na escola; do Estatuto da Criança e do Adolescente, Lei no 8.069 , de 13 de julho de 1990, que protege os direitos das crianças e dos adolescentes. Nos termos do Art. 227 da Constituição Federal, que prevê o direito à saúde, à vida, à alimentação, à educação dentre outros; de acordo com o Artigo 1ำ da Lei de Diretrizes e Bases da Educação Nacional que prevê a abrangência dos processos formativos que se desenvolvem na vida familiar e comunitária. Apoia-se ainda no Artigo 217 da Constituição Federal, que prevê o direito da criança e o dever do estado no sentido de oportunizar atividades esportivas como parte da formação integral.
} 
a educação novamente do zero, mas sim, adequar o conhecimento, as estratégias e as políticas públicas à realidade da educação integral e da comunidade/sociedade escolar. Ela vem para complementar o processo de ensino-aprendizagem, uma vez que, segundo Gadotti (2009), nós aprendemos durante toda a vida, não teríamos como separar um período no qual aprendemos e no outro não, logo o correto seria falar de educação em tempo integral, pois aprende-se em todo e qualquer lugar, na escola, na família, na sociedade e etc.

Conforme o projeto educativo em curso nas escolas, quatro atividades são escolhidas dentre as mais diversas possibilidades ofertadas. Uma destas atividades deve, obrigatoriamente, compor o macrocampo acompanhamento pedagógico. O detalhamento de cada atividade em termos de ementa e de recursos didático-pedagógicos e financeiros previstos é publicado anualmente em manual específico relativo à Educação Integral, que acompanha a resolução do Programa Dinheiro Direto na Escola (PDDE) do FNDE. O caderno Passo a Passo Mais Educação detalha, de forma objetiva, o público alvo do Programa, os profissionais responsáveis, o papel do professor comunitário/professor coordenador, os macrocampos e as atividades, além de dar outras orientações. O programa é coordenado pela Secretaria de Educação Básica (SEB/MEC) com parcerias com as Secretarias Estaduais e/ou Municipais de Educação.

A sua operacionalização é feita por meio do Programa Dinheiro Direto na Escola (PDDE) e pelo Programa Nacional de Alimentação Escolar (PNAE), do Fundo Nacional de Desenvolvimento da Educação (FNDE).

Em 2014, era prevista a adesão de 60.000 escolas em todo o país, atingindo em torno de 7 milhões de estudantes. Escolas que se apresentam com $50 \%$ ou mais de estudantes participantes do Programa Bolsa Família, mantêm-se prioritárias para o atendimento, considerando a intersetorialidade do programa com o Ministério do Desenvolvimento Social (MDS), por meio do Programa Brasil Sem Miséria.

\section{A EDUCAÇÃO EM TEMPO INTEGRAL ATRAVÉS DO PROGRAMA MAIS EDUCAÇÃO}

A educação em tempo integral tem como finalidade incluir o estudante do ensino fundamental na escola por mais tempo, ou seja, no mínimo sete horas diárias para melhorar a qualidade da aprendizagem do aluno. Visando pôr em 
prática esta modalidade de ensino, criou-se em 2007 o Programa Mais Educação do Governo Federal.

Concordando com a ideia de que para se ter uma educação em tempo integral eficaz, não se deve ter somente atividades de aulas ministradas pelos professores, destaca-se o que diz a professora Bernardete Gatti (2006):

Esta ampliação comportaria um processo educativo pensado segundo outras premissas, realizado por atividades, oficinas, experiências, onde (sic) os alunos pudessem trabalhar, não só com os saberes, mas com coisas, cultivar artes aplicadas, cultivar elementos artísticos, criar projetos e desenvolvê-los, sob orientação de profissionais diversificados. (apud GUARÁ, Isa Maria F. Rosa)

Como se pode perceber, é necessário possuirmos atividades diferenciadas para que a educação em turno integral venha enriquecer e ampliar o conhecimento do estudante, favorecendo, assim a melhor convivência social e desempenho em suas atividades profissionais no seu dia-a-dia. Nesse sentido o Programa Federal Mais Educação oferece oficinas em turno inverso, ao que o estudante frequenta as aulas, contribuindo, de certa forma, para a educação em tempo integral.

$\mathrm{Na}$ atualidade, a maioria das escolas funciona de forma rotineira, em um único turno e voltadas unicamente para repassar conteúdos através de suas disciplinas, fato que já não contribui, na realidade, para uma formação mais ampla. E para mudar esta situação uma das alternativas seria adotar a escola de tempo integral, que, segundo Gadotti (2009), a participação dos pais é de extrema importância. A escola que adotar o tempo integral, precisa saber que em seu Projeto Político Pedagógico terá de ter sido incluso o conhecimento formal, não formal e informal.

Gadotti defende a implantação de um sistema escolar que funcione em tempo integral. E para isso é necessário e importante a presença e participação dos pais, da comunidade como um todo, e a presença de alunos em tempo integral na escola. A escola por sua vez deve elaborar um Projeto Político Pedagógico, de forma coletiva, que seja prático e funcional com a finalidade de realizar atividades educativas amplas, abrangentes, além das aulas normais. A escola em Tempo Integral viria a preparar o aluno para melhor viver, conviver, contribuir e desempenhar o seu papel como cidadão no âmbito familiar, pessoal, social e 
profissional.

Muitas vezes confunde-se a Escola de Tempo Integral com a Educação Integral, uma vez que ambas são parecidas, mas não são iguais. Quem discute isso é a professora e dirigente da Diretoria de Educação Integral, Direitos Humanos e Cidadania Jaqueline Moll, que afirma:

[...] de nada adiantará esticar a corda do tempo: ela não redimensionará, obrigatoriamente, esse espaço. E é, nesse contexto, que a educação integral emerge como uma perspectiva capaz de re-significar os tempos e os espaços escolares. (2009, p.18)

Moll (2009), sustenta que não basta aumentar o tempo e o espaço, na questão da escola em tempo integral, pois de nada adiantará para a melhoria da qualidade do ensino/aprendizagem. Assim sendo, a autora argumenta que é necessário melhorar as condições de trabalho, qualificando e formando 0 professor para esta finalidade e também aperfeiçoar, inovar e equipar o espaço para viabilizar e ofertar esta modalidade de ensino aos alunos, melhorando, assim, a sua sociabilidade e a integração com a sua comunidade local, regional e global.

Muitas foram as tentativas, apesar de metodologias diferentes de implantála. No momento o debate público se torna mais forte, como afirma Gouveia (2006, p.84) o assunto da "educação integral" torna a ser discutido publicamente, depois de alguns anos, compreendendo-a como "um caminho para garantir uma educação pública de qualidade." Segundo ele, é um bom caminho para se implantar e garantir a educação pública de qualidade, qualificando, desta forma, os estudantes, preparando-os melhor para a vida.

Podemos dizer ainda que todos os órgãos com responsabilidades educacionais no Brasil, independente das esferas às quais pertençam, podem e devem se unir e contribuir cada qual com o seu poder e alcance para que tenhamos uma educação, uma escola, uma comunidade e um corpo docente e discente não apenas melhor preparados, mas também habilitados a viver e conviver em comunidade e com a Educação em Tempo Integral.

\section{A IMPORTÂNCIA DA LEITURA}

$O$ ato de ler pode representar, para as pessoas não habituadas, uma atividade cansativa. Já aqueles que desenvolveram o gosto pela leitura, leem por 
prazer sem sentir cansaço e principalmente como uma das melhores fontes de informação. O "ideal” seria mesclar a prática leitora com o hábito da leitura, com o gostar de ler, de sentir prazer e ao mesmo tempo a sede pela busca de novos conhecimentos. $\mathrm{Na}$ atualidade, temos uma compreensão muito clara a respeito da importância da leitura, as pessoas que não possuem o habito de ler, veem tal ação como algo tedioso e não conseguem ampliar os seus horizontes de formas práticas, pois é nos livros que existe a chance de se atualizar e obter novos conhecimentos.

As pessoas não leitoras acabam restringindo o seu grau e nível de conhecimento, uma vez que se comunicam, conversam e aprendem apenas oralmente em conversas com grupos de amigos ou colegas de trabalho. É nos livros que buscamos o desconhecido e é através deles que conhecemos fatos históricos, lugares, "abrimos" nossa cabeça e passamos a ter uma melhor convivência e visão do mundo e da vida.

Ler é uma forma de melhorar o aprendizado, tanto pela vida quanto para fins escolares, pois, conforme afirma Lück (2006, p. 8-9), "para melhorar a educação é necessário começar pela leitura”. Ela é um meio que se faz necessário para melhorar a educação e contribuir para uma melhor formação do estudante e do cidadão. Ler é um aprendizado que contribui para a melhoria do ato de se expressar do estudante. Freire (apud Antunes, 2002) afirma que:

[...] o aprendizado da leitura [...], associado ao necessário desenvolvimento da expressividade, se faz com o exercício de um método dinâmico, com o qual educandos e educadores buscam compreender, em termos críticos, a prática social. (p.65).

Segundo o autor, melhora-se a expressividade através da leitura, uma vez que ocorre um exercício numa dinâmica que permite ao educando e também aos educadores compreender através de análise crítica, vivenciar sua prática social.

Muitas vezes, como professor, é muito válido refletir sobre o tipo de livro que estão indicando aos alunos, pois, segundo Lajolo (1997), não foi antes dos anos de 1950 que a ideia de adolescência chegou ao Brasil e com ela veio a classificação dos livros infanto-juvenis. A função/reflexão que recai sobre o professor é se esse tipo de literatura agradará e fará com que o estudante se torne um leitor mais assíduo e, anos mais tarde, venha a ler e gostar dos clássicos, 
como por exemplo Memórias Póstumas de Brás Cubas.

Segundo o professor Ezequiel Theodoro da Silva, "os melhores parceiros para a promoção da leitura que tem um potencial inesgotável, que são os mais solidários com as nossas causas, são os próprios alunos de uma escola com quem convivemos diariamente." (SILVA, 1991, p.12)

Muitas vezes a leitura pode ser muito mais do que um método de adquirir conhecimento, como nos diz Márcia Abreu (2002): "a leitura não é uma prática neutra. Ela é campo de disputa, é espaço de poder" (p.15). Conforme a autora, a leitura é um instrumento que não apenas informa e melhora os conhecimentos do leitor, como também, Ihe dá poderes. Gutenberg inventa a prensa móvel, utilizando tinta e moldes que eram prensados em suas formas, produzindo letras que passaram a ser impressas em pergaminho e papel. Um século mais tarde, com a natural evolução e revolução da máquina a vapor, temia-se pelo fim da impressão, seguindo essa ideia. Com a chegada de um produto novo, o anterior iria desaparecer, na seguinte sequência: o livro devido à máquina; a pintura devido à foto; o jornalismo impresso devido ao rádio; e todos esses meios de comunicação seriam extintos com a chegada da televisão, e que nos dias atuais o livro novamente estaria em perigo devido à chegada da internet, que revolucionou o mundo da comunicação.

Ler, talvez, seja tão importante quanto se alimentar, pois enquanto os alimentos dão vitalidade ao corpo, a leitura alimenta a alma, rejuvenesce o espírito, educa e reeduca cidadãos, estando eles em fase de estudos escolares ou não, permitindo que o leitor se sinta integrado, inserido, envolvido e bem relacionado, tanto familiar, social, quanto virtualmente. Além de servir como lazer, ainda auxilia no processo de ensino-aprendizagem, melhorando não apenas o conhecimento, mas também permitindo ao aluno ou ao ser humano melhor falar, compreender, se comunicar e conviver socialmente.

\section{O UNIVERSO DA LEITURA NO PROGRAMA MAIS EDUCAÇÃO NA}

\section{ESCOLA BANDEIRANTES}

A pesquisa foi estruturada tendo como referencial a pesquisa qualitativa. Através desta, busca-se decifrar o que está explícito e também implícito nas respostas do instrumento de pesquisa. De acordo com Ribeiro (2006): 
Pesquisar qualitativamente é, antes de qualquer outra definição, respeitar o ser humano em sua diversidade. É entender que há singularidade em cada uma das pessoas envolvidas e que essa singularidade é construída na pluralidade; nas múltiplas etnias, nas pluri-manifestações culturais, corporais, lingüísticas. É gostar de ser gente. (apud Magalhães e Albino, 2010, p.5)

Assim, pesquisar de forma qualitativa é respeitar as diferenças existentes em cada ser humano. Existem diversas formas e técnicas de coletas de dados. Utilizou-se nesta pesquisa um questionário, que se caracteriza por um conjunto de perguntas, que foi lido e respondido, sem a necessidade da presença de um entrevistador

Foi aplicado questionário para dez alunos da escola, com o objetivo de verificar quais suas expectativas com relação ao Programa Mais Educação. Dentre várias questões feitas durante a pesquisa, duas são explanadas aqui, a primeira, sobre quantos livros os alunos haviam lido no Programa Mais Educação, obteve-se o seguinte resultado: um aluno (10\%) disse que leu mais de dez livros; dois alunos (20\%) responderam que leram de 6 a 10; quatro alunos (40\%) disseram que leram de 1 a 5 livros, enquanto que três alunos (30\%) informaram que não leram nenhum livro através do Programa Mais Educação. Em resposta à questão: O que mais chama atenção nas obras que lê?, obteve-se as seguintes informações: o aluno que leu Harry Potter e o Prisioneiro de Azkaban, destacou a ação que gira entorno da história; O aluno que leu O Senhor dos Anéis, destacou a criatividade dos autores que inventam livros incríveis; a aluna que leu Violetas na Janela, relatou que sempre aparece um personagem legal; a estudante que leu Otalina e a Gata Amarela, escreveu que o que Ihe chama atenção é algum personagem e os fatos; por sua vez a aluna leitora do livro Fadas, Duendes e Guinomos disse que as fadas lhe chamaram a atenção e a leitora do livro Sofia e o Bosque Encantado, expôs que a história é o que mais lhe chama atenção.

Com os dados coletados e a análise da pesquisa possibilitou-se concluir que tanto a direção quanto os profissionais envolvidos no Programa Mais Educação da Escola Estadual de Ensino Fundamental Bandeirantes, estão imbuídos de grande empenho e um espírito coletivo no sentido de fazer com que este trabalho continue, pois vem frutificando e trazendo bons resultados tanto em âmbito escolar, sala de aula, quanto em família, contribuindo, desta forma, para uma melhoria na qualidade de ensino e de convivência social. 
Neste sentido, pode-se afirmar que a leitura deve ser oportunizada, oferecida e estimulada aos estudantes de todo estabelecimento de ensino e por todos os profissionais que nele atuam, pois com a união de todos, sem medir esforços, é possível melhorar o ambiente de leitura, criar novos métodos, visando estimular o estudante a gostar de ler e, para que isto ocorra e frutifique, é também importante e necessário ampliar e qualificar o acervo bibliográfico, com obras apropriadas a cada faixa etária.

Assim sendo, conclui-se que toda e qualquer prática leitora exerce importante influência na formação de novos leitores e além disso também contribuem no sentido de aprimorar, tornar habitual os estudantes que já leem. Pode-se afirmar que é possível desenvolver o gosto pela leitura prazerosa além de oportunizar conhecimento, melhorar a oratória e a construção frasal. $O$ exemplo de professores e alunos pode estimular os não leitores a se envolver no mundo dos livros. 


\section{REFERÊNCIAS}

ABREU, Márcia. Prefácios: Percursos da Leitura. Em: (org.). Leitura, história e história da leitura. Campinas, SP: Mercado das Letras, Associação de Leitura do Brasil; São Paulo: FAPESP, 2002.

AZEVEDO, Fernando. Et al. construção educacional no Brasil: ao povo e ao governo; manifesto dos Pioneiros da Educação Nova. São Paulo: Nacional, 1932 - disponível em $<$ http://www.dominiopublico.gov.br/pesquisa/DetalheObraForm.do?select_action $=\&$ co_obra $=205210>$ acesso em: 03 de abril

BRASIL. Educação integral: texto referência para o debate nacional. - Brasília: Mec. Secad, 2009 - Disponível em: $<$ http://portal.mec.gov.br/dmdocuments/cadfinal_educ_integral.pdf>

. Portal do Programa Mais Educação. Disponível em:

$<$ http://portal.mec.gov.br/index.php?option=com_content\&id=16689\&ltemid=1115 > - acesso em 12 de março de 2015

Decreto $\mathrm{n}^{\circ}$ 7.083, de 27 de Janeiro de 2010, dispõe sobre o Programa Mais Educação, Diário Oficial da União Brasília. Brasília, D.F, 2010 - acesso em 12 de março de 2015

, MEC. Portaria Normativa Interministerial n 17, de 24 de abril de 2007. Institui o Programa Mais Educação que visa fomentar a educação integral de crianças, adolescentes e jovens, por meio do apoio a atividades socioeducativas no contra turno escolar. Diário Oficial da União, Brasília, DF, 26 abr. 2007a.

Manual operacional da educação integral. 2014. Disponível em: <http://educacaointegral.mec.gov.br/mais-educacao> - acesso em 12 de março de 2015

Senado Federal. Lei de Diretrizes e Bases da Educação Nacional: nº 9.383, de 20 de dezembro de 1996. Disponível em: < http://www.planalto.gov.br/ccivil_03/leis//9394.htm> Acesso em: 12 de março de 2015

. Lei no 10.172, de 9 de janeiro de 2001. Aprova o Plano Nacional de Educação e dá outras providencias. Disponível em:<http://www.planalto.gov.br/ccivil_03/leis/leis_2001//10172.htm> Acesso em: 24 de abril de 2015

FOUCAMBERT, J. A leitura em questão. Trad. de Bruno Charles Magne. Porto Alegre: Artes Médicas, 1994.

FREIRE, Paulo apud ANTUNES, Ângela. Leitura do mundo no contexto da planetarização: por uma pedagogia da sustentabilidade. São Paulo: FE-USP, 
2002.

GADOTTI, Moacir. Educação Integral no Brasil: inovações em processo - São Paulo: Editora e Livraria Instituto Paulo Freire, 2009. - (Educação Cidadã; 4)

GATTI, Bernadete, apud GUARÁ, Isa Maria F. Rosa. É imprescindível educar integralmente. In: Caderno CENPEC: educação, cultura e ação comunitária, n. 2, p. $15-24,2006$

GOUVEIA, Maria Júlia Azevedo. "Educação integral com a infância e a juventude". In: Educação integral. Cadernos Cenpec, apud GADOTTI, Moacir. Educação Integral no Brasil: inovações em processo - São Paulo: Editora e Livraria Instituto Paulo Freire, 2006.

LAJOLO, Marisa. Poesia uma frágil vítima da escola. São Paulo. Ática, 1997. LÜCK, Heloísa. A gestão pedagógica da escola focada na leitura. Gestão em Rede, Curitiba, PR, n 73, p. 8-9, out 2006.

MAGALHÃES, Solange Martins Oliveira; ALBINO, Larissa Carneiro. A pesquisa qualitativa nas produções acadêmicas sobre professores do Programa de PósGraduação em Educação da UFG. In: Anais do XIX Simpósio de Estudos e Pesquisas. Universidade Federal de Goiás. Faculdade de Educação. ISSN 2179-0213. 2010. Disponível em: http://anaisdosimposio.fe.ufg.br/n/30787comunicacoes-formacao-e-profissionalizacao-docente-pagina-1. Acesso em: 26. mai. 2015.

MOLL, Jaqueline. (Org.). Educação integral: texto referência para o debate nacional. Brasília: MEC/Secad, 2009.

SILVA, Ezequiel Theodoro da. De olhos abertos: reflexões sobre o desenvolvimento da leitura no Brasil. São Paulo: Ática, 1991. 